\title{
The great grunion run
}

\section{Monitoring grunion runs to inform conservation}

Grunion runs describe the unusual breeding behaviour of the California grunion, which come ashore on sandy beaches to spawn. Fertilised eggs then incubate in the sand and only hatch when scouring waves rom the next spring tide traits leave both adult fish and eggs vulnerable to negative human impacts. Professor Karen L. M. Martin from Seaver College, Pepperdine University, coordinates a citizen science project which monitors the grunion runs to gather information on the conservation efforts.

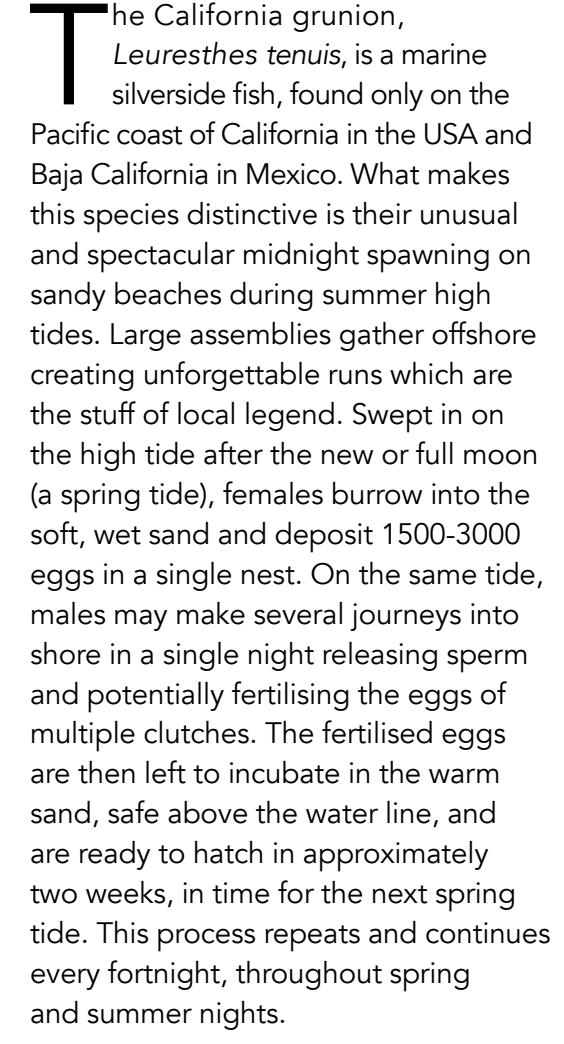

WHAT ARE THE PROBLEMS? the California grunion particularly vulnerable to human activity. These fantastic beach spawning events have enthralled generations. However, it also led to a local culture of recreational fishing durng spawning events which resulted in severe overharvest and ef the op the population. Many some of the most popular coasta destinations for daytime human visitors in southern California. To cater for the visitors, beaches are raked and graded to remove rubbish, and lifeguard and other public safety vehicles patrol the shoreline creating disturbance which can destroy incubating eggs.

In addition to these direct human activities, climate change impacts and an ever-increasing human population exacerbate the problems facing the California grunion. Coastal squeeze,
caused by the combination of human

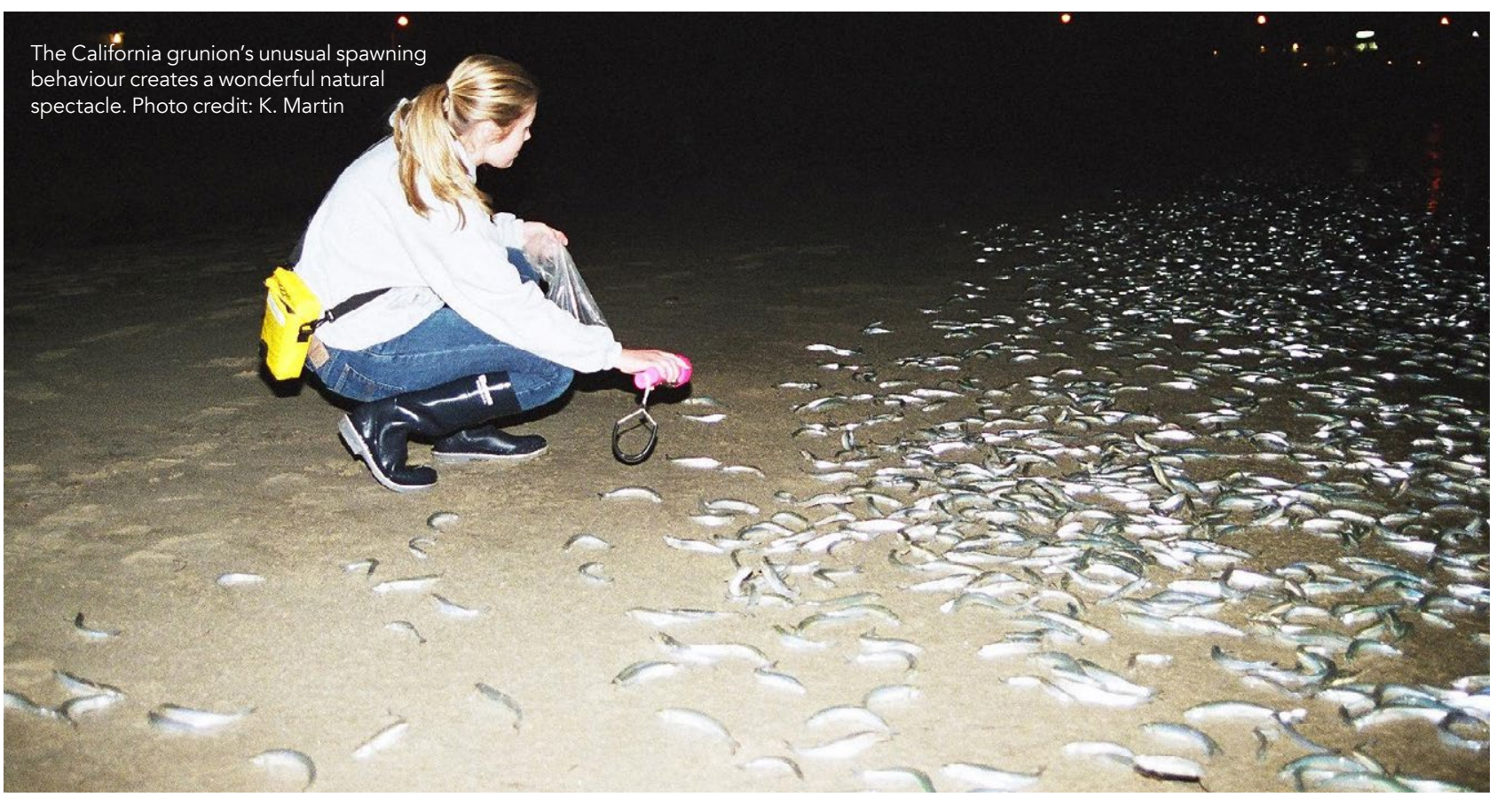

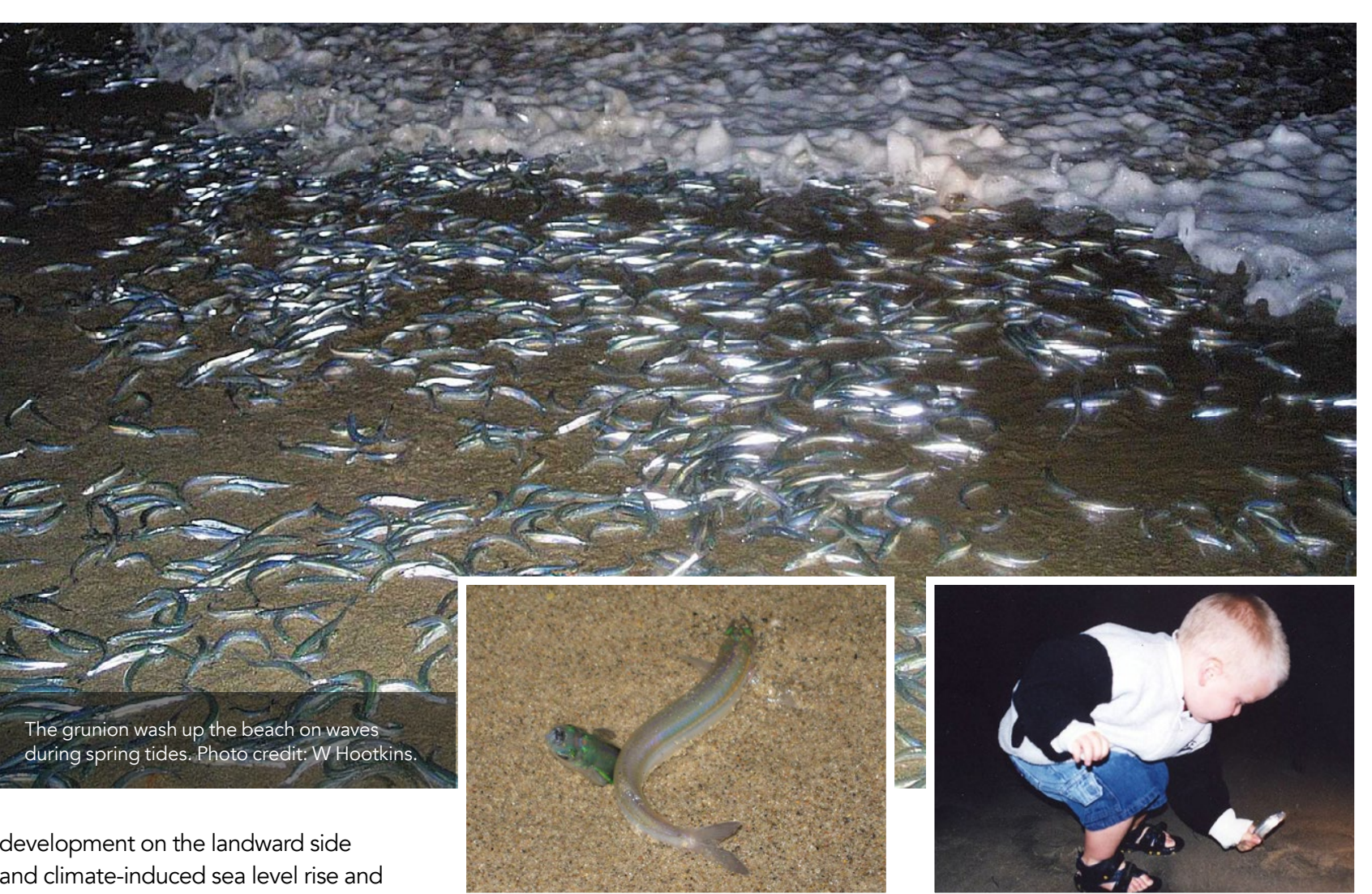

and climate-induced sea level rise and the available habitat for many coastal. plants and animals. For beach-spawning fishes this loss of critical spawning habitat will have a direct negative impact on ecruitment into the next generation. As well as sea level rise, climate change also causes ocean warming. Temperature plays a part in sex determination of California grunion with warmer temperatures in ealy Iffe increasing the proportion of males, which will have knock-on consequences for recruitment into the next gener

To add to the problems, California grunion are rarely caught in traw so these traditional fisheries methods for gathering population data are unsuccessful. This has left a significan gap in knowledge and understanding of population trends for the species which are vital to inform effective conservation management strategies.

\section{CITIZEN SCIENCE:}

\section{RUNION GREETERS}

Since 2002 Professor Karen Martin from Seaver College at Pepperdine University Malibu, has directed the 'Grunion This projs citizen science programme. This project monitors ky aspects of the The female grunion burrow into the sand to
laytheir gygs while the males release sperm to
fertilise them. Photo credit: D Martin.

All ages are welcome in the Grunion Greeters

Observations of runs can be dazzling, with thousands of fish moving out onto shore from waves for an hour or more.

the geographical range, generating an important long-term data set made up of over 5000 reports to date. Grunion 1) Greeter volunteers are trained to assess duration, and 3) the extent of shoreline, during the peak of the run. The measures are known as the 'Walker Scale' after scientist Boyd Walker who single-handedly every night for three years, and in 1947 initiated his own early citizen science project by enlisting the help of volunteers across California. Today's citizen scientists also report on the weather, features of the habitat, and human and predator behaviour during the grunion run. Data are submitted via a web portal and so are instantly available to the scientists. Analysis of the data to understand reliability of citizen scientist observations shows the data to be highly reliable, with observers agreeing $87.6 \%$ of the time in their use of
the Walker Scale to rank spawning runs. Data collected by the dedicated Grunio gathered data on grunion runs almost
WHAT HAS THE PROJECT FOUND? highly variable across locations and are declining across the species range. ranking on the Walker Scale was W2, described as a 'oood run' and indicating However, from 2010 to 2018 this ranking dropped to a median of W1, a light run" with fewer than 100 fish at the peak. Furthermore, a median of WO 'no run' with little or no spawning was recorded in both 2014 and 2016. Occasional large uns are still observed. However, this is likely a result of a tendency for this species popyega, which could mask total population declines.

The data also indicates a northward shitt in range for the California grun Howhly variable across locations and days. From 2002 to 2010 the median average 100-500 fish at the peak during a run. 


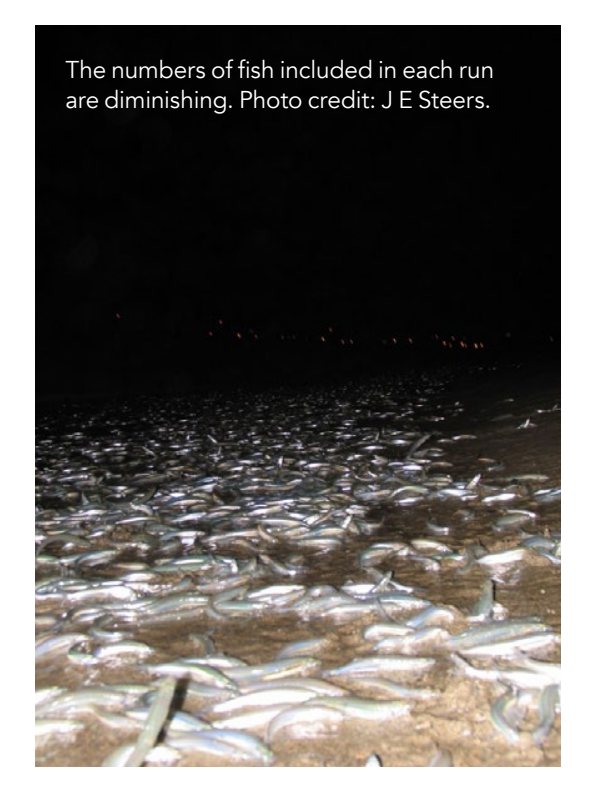

identified across animal and plant taxa as a response to climate change. California grunion is smaller and spawns less frequently producing fewer, smaller eggs per clutch. These phenotypic changes to key life-history traits result in a reduction in reproductive output and

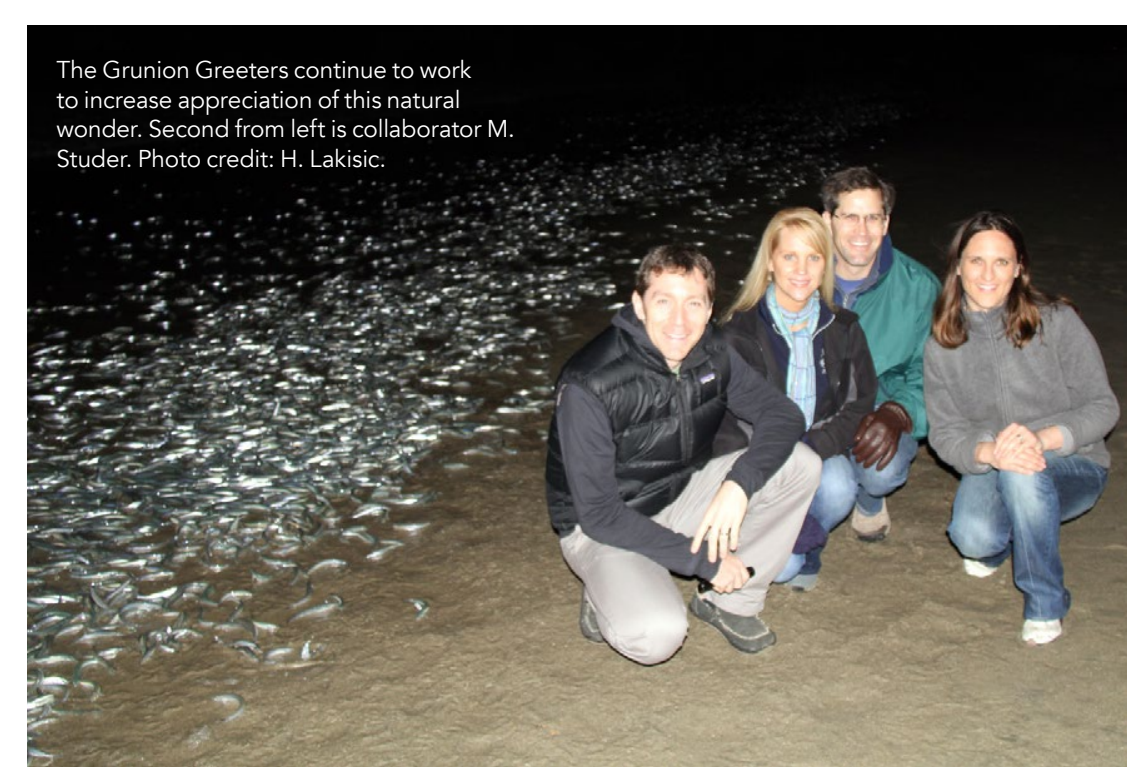

have been put in place to try to manage the California grunion population and is allowed across the peak spawning season in April and May and even ousto of this time, anyone 16 or over must have a licence. Fishing gear is mann so people can only catch the fish with

All should be able to simply enjoy the amazing sight of California's original surfers dancing on the beach.

suggest the range shift alone will not be their bare hands. However, data from enough to stabilise the population in the face of climate change.

Recreational fishing during spawning runs has long beon part the Grunion Greeters project showed enforcement of these measures to be low, and recreational fishing continues to impact spawning runs. The data also from people wating on the shorline

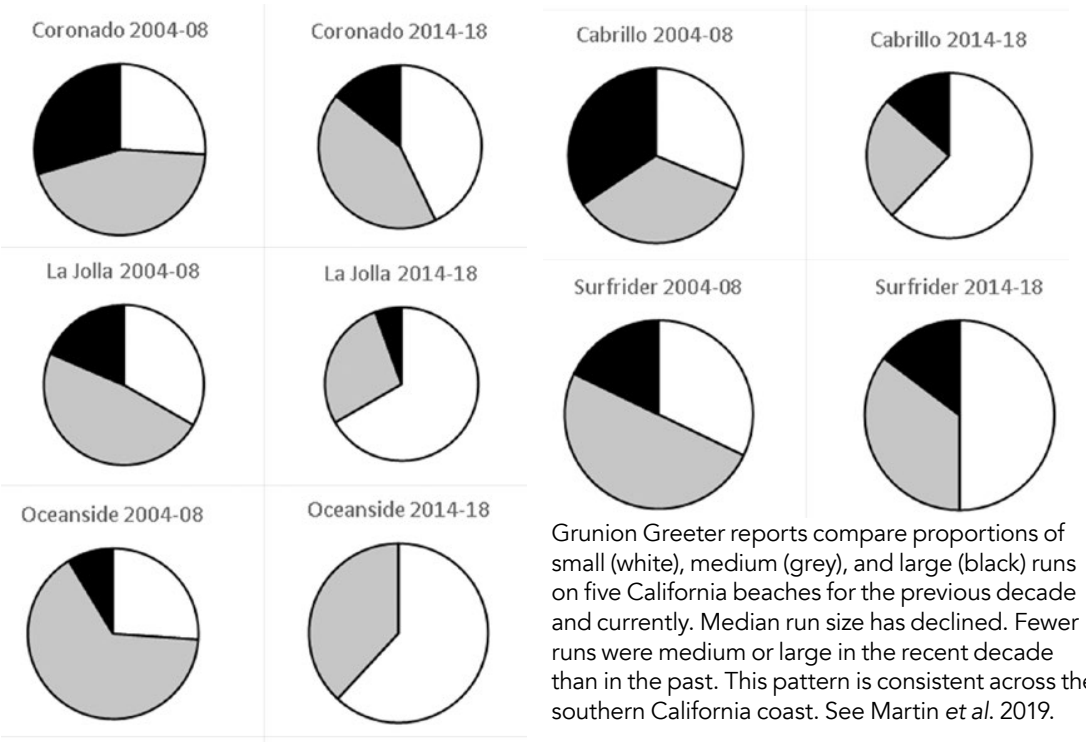

disrupting the run and preventing spawning before fish are caught.

\section{CONSERVATION MANAGEMENT} Data for this successful citizen science project is playing a crucial role in Greater understanding of the grunion run has informed beach management. and beach maintenance for visitors is now restricted to above the hightide line to reduce disturbance and damage to nests. However, the decline in the number and size of grunion runs across the range suggests either total population decline and/or inability to spawn, both of which lead to a reduction in reproductive output. are calling for greater protection, particully a round recreational fishing to significantly impact spawning and therefore long-term population and This highly charismatic species is climate change on beach ecology and further work is needed to understand how these can be mitigated. Finally, the Grunion Greeters continue to work to shift perceptions towards an appreciation of the wonder of the grunion run as a truly inspiring natural spectacle.

Find out more about this longproject at www. grunion. org or www beachecologycoalition.org, with updates also posted on Instagram using
the hashtag \#BeachEcologyCoalition. Prof Karen Martin and colleagues also a key indicator of the impacts of standing, successful citizen science

\section{Behind the Research}

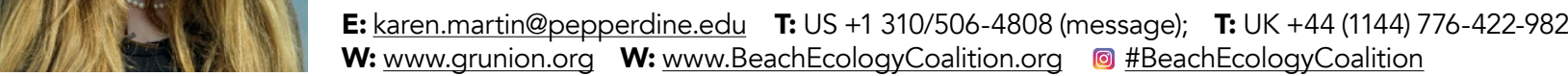

\section{Research Objectives}

Prof Martin runs a citizen science project to monitor numbers of the California grunion fish.

\section{Detail}

Pepperdine University 24255 Pacific Coast Highway Malibu, CA 90263, USA

Bio

Dr Martin has written three scholarly books, 50+ journa articles / book chapters on coastal ecology, amphibious fishes, and the transition from water to land. She cofounded the citizen science group, Grunion Greeters and Beach Ecology Coalition, a nonprofit organisation to balance human recreation with conservation. PhD, UCLA; Postdoctoral Fellow, Friday Harbor Laboratories; Distinguished Professor, Pepperdine University.

Funding

US Fish \& Wildlife Service, "Connecting People with Nature" California Coastal Commission Whale Tail Program WT-13-22 National Science Foundation DBI 1062721

USC S Science Foundation, ReU-1560352 USC Sea Grant College - Urban Oceans Program Marine Fisheries Service, Southwest Region, hibitat National Georaphic

ciety CRE 8105-07

Pepperdine University

\section{Collaborators}

- Emily Pierce, Moss Landing Marine Laboratory - Melissa Studer, Grunion Gricago

$$
\text { Grunion Greeters }
$$

(6) PEPPERDINE

\section{References}

Martin, KL. and Studer, M. (2019). Grunion Greeters: Citizen Science on the Beach [olline]. Grunion.org. Available at: $:$ htpp://
grunion.pepperdine.edu/default.htm [Accessed 15.09.2019]. Beach Ecology Coalition (2017). Beach Ecology Coalition
[online. Available at: www.beachecologycoalition.org [Accessed 15.09.2019].

Martin, KLM., Pierce, EA., Quach, W. and Studer, M. (2019). Population trends of beach-spawing Califormina grunion

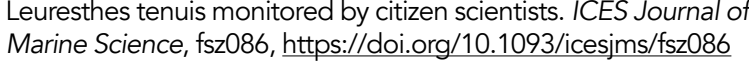
Martin, KL. (2015). State of the Bay Report. Biodiversity: California Grunion. Urban Coast, 5 (1), pp.150-156. Available at: http:// urbancoast.org/ [Accessed 15.09.2019

Martin, KLM., Hieb, KA. And Roberts, DA. (2013). A Southern Calfirmia con Surts North: Local Ecotype of Califormia Grun
Leuresthes tenuis (Atherinopsidae), Revealed by Multiple Approaches during Temporary Habitat Expansion into San Cl-13-036

Martin, KL. (2010). The Legendary Grunion of Cabrillo Beach.

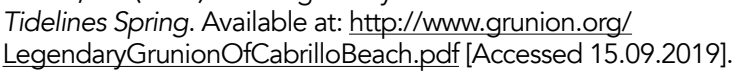
Martin, KL., Staines, A., Studer, M., Stivers, C., Moravek, C., Joeach spawning fish, costal stewardship, beach management and ecotourism. pp.73-86. In: Luck, M., Graupl, A., Auyong, J., Miller, ML., and Orams, M. (eds). Proceedings of the 5th International Coastal \& Marine Tourism Congress: Balancing
Marine Tourism, Development and Sustainability, AUT University,
Auckland, NewZZealand. Auckland, New Zealand.

\section{Personal Response}

Does the decline in California grunion have knock on

III Yes, the species is a forage fish that is eaten by many pelicans, and guitarfish Some fish ans, dolphins, hallibut, the water chasing grunion during runs. On these nights, Great Blue Herons and Night Herons are often seen hunting the fish between the waves. Grunion eggs and young are favourite foods of some endangered shorebird Knot and the Least Tern. These fish provide important high-quality food to birds during their critical reproductive high-quality food to birds during their critical reproductive
periods and as they migrate along the Pacific Flyway. 